\title{
EXPLORING A CONCEPTUAL MEASUREMENT INSTRUMENT TO ASSESS PERFORMANCE PREDICTORS OF SMALL TOURISM BUSINESS IN SOUTH AFRICA
}

\author{
Van Zyl HJC and Mathur-Helm B, University of Stellenbosch Business School, South Africa
}

\begin{abstract}
Purpose: The present study was set out to develop a model of entrepreneurial leadership that can recognize success factors of the owners of small and micro tourism enterprises within the South African context. The study attempts to combine various reliable and valid measurement instruments together, in conceptualising a more comprehensive and unified model that could test the nature and extent of the interrelationships between entrepreneurial leadership, market orientation, relationship marketing orientation and small tourism performance identified in a previous study by Van Zyl and Mathur-Helm (2007). Hence, a complex measurement instrument was conceptually constructed by the present study.
\end{abstract}

Problem Investigated: The Van Zyl and Mathur-Helm's (2007) study found that entrepreneurial leadership could best be described through a combination of distinct components. Hence the following instruments, entrepreneurial proclivity, ethical orientation, revised self-leadership, market orientation and relationship marketing orientation, with wide ranging dimensions of entrepreneurship, tourism, marketing and leadership, were brought together in formulating a comprehensive and complex measurement instrument.

Methodology: It is a descriptive and a theoretical article that conceptually describes the development of a complex measurement instrument and thus secondary data from previous studies are used as comparative analysis for discussions and examinations.

Implications: The paper recommends implications for South Africa's small tourism businesses, the government and the training institutions, by suggesting a model of performance predictors that can measure entrepreneurial leadership and can distinguish between successful (performing) and unsuccessful (non-performing) owner-managers of such ventures. Moreover, the instrument is aimed at providing insights into the kind of skills that a particular entrepreneurial leader and/or an owner manager of a small tourism enterprise may need in order to perform optimally in a complex and competitive environment.

Originality and Value of Research: The present study will add immense value as South Africa is one of the most popular tourist destination that stands a good prospect of expanding its opportunities for the existing and upcoming tourism ventures. Hence owners, managers and leaders of small tourism enterprises demonstrating leadership characteristics such as high internal locus of control, autonomy and achievement drive, through awareness of such characteristics and acquiring them through skills development will be able to build high performing future businesses.

Conclusion: The complex measurement instrument constructed in the present study, by combining the existing tools: entrepreneurial proclivity instrument (Matsuno et al., 2002); ethical orientation instrument (Forsythe, 1980); revised self leadership instrument (Houghton and Neck, 2002); market orientation instrument (Narver and Slater, 1990); relationship marketing orientation instrument (Sin et al., 2002) and small tourism performance (Lerner and Harber, 2000; Wood 2002 and 2006) would help in identifying the vital entrepreneurial characteristics described through a combination of different dimensions.

Key words and phrases: Ethical Entrepreneurial Self-leadership, construction of a measurement instrument, market orientation, relationship marketing orientation, small business performance.

\section{INTRODUCTION}

In his best selling book 'Good to great companies' (Collins, 2001), Jim Collins wrote what it takes for the leaders of the great performing companies to make the transition from being good to becoming great, and concluded that the success lies in the organisational culture. Similarly, there are vital entrepreneurial characteristics that drive certain people to initiate and grow small tourism businesses successfully, while others fail. Van Zyl and Mathur-Helm (2007:17-24) in their study on performance predictors for small tourism enterprise, found a link between entrepreneurial qualities and the small business performance. Hence they developed a model for predicting performance of entrepreneurs by using the concept as shown in figure 1 below. 
While, personal qualities of the small business owners such as market orientation and relationship marketing orientation directly impact the business performance and the strategic orientation of the business. A successful entrepreneurial behaviour depends upon how well the business model is anchored on a well positioned strategy.

Given that retaining customer is more cost effective than constantly finding new ones, the entrepreneurial leaders should have the proclivity towards the market challenges and competitive edge. They should ensure that they have high customer and competitive orientations and are inclined towards building the long term sustainable relationships with their customers and clients.

The Van Zyl and Mathur-Helm's (2007:17-24) study hypothetically established the intricate interplay between the entrepreneurial leadership (EL), market orientation (MO) and relationship marketing orientation (RMO) by identifying ways in which the entrepreneurial leadership qualities affect the business and to orient itself appropriately towards the market, thus further signifying that personal qualities of small business owners are the backdrop of an improved business performance. However, the study did not examine empirically the exact nature, extent and the effect of the interface within the constructs.

Therefore, purpose of the present study is to answer the following questions:

- How to create a comprehensive and unified measurement instrument that can reliably measure the conceptualized relationships between the identified constructs in the VZMH model?

- How to identify a suitable data analyses technique that could determine the nature and extent of the interrelationships between the latent constructs in the conceptualized VZMH model?

The present paper aims to investigate personal qualities of the small business owners, the business, and the environment of the business, by using systems approach as it recognizes the complex interplay between the varying characteristic in the VZMH model. The study will conceptually bring together diverse perspectives in formulating a more comprehensive and unified instrument for measuring entrepreneurship in the small tourism industry.

\section{Figure 1: Conceptual measurement model}

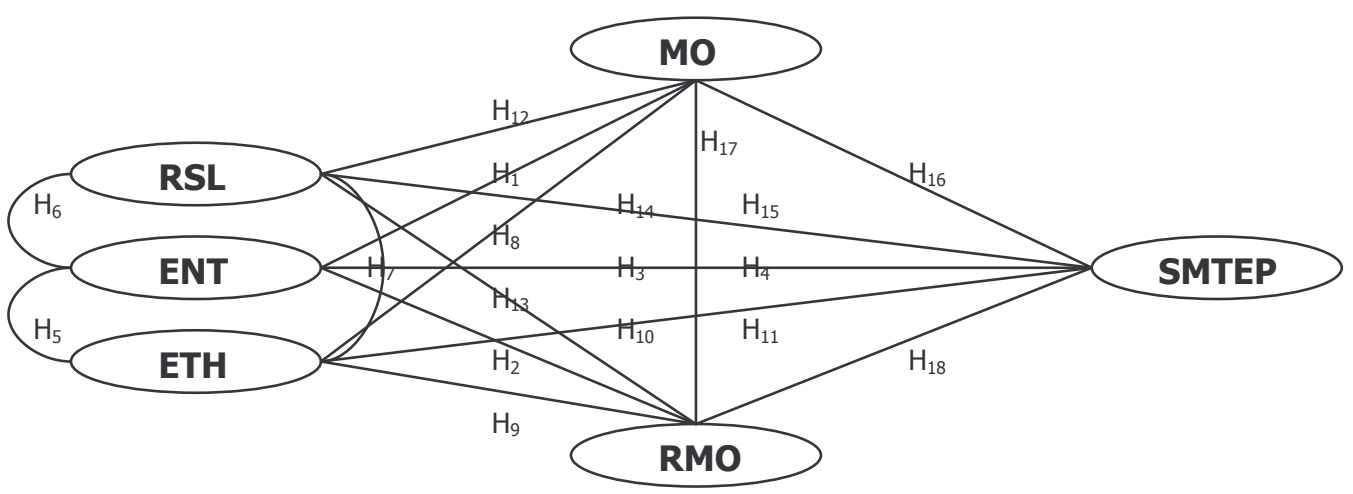

Source: Van Zyl and Mathur-Helm (2007).

Key: $\quad \mathrm{RSL} \quad=$ Revised Self-leadership

ENT = Entrepreneurship orientation

$\mathrm{ETH}=$ Ethical orientation

$\mathrm{MO}=$ Market orientation

$\mathrm{RMO}=$ Relationship marketing orientation

SMTEP = Small and micro tourism enterprise performance

$\mathrm{H}_{\mathrm{a}} \quad=$ Proposition/Relationship between two constructs 


\section{DIMENSIONS OF INTERNAL AND EXTERNAL BUSINESS SYSTEMS}

The present study distinguishes small and micro size tourism enterprises (SMTE) from the medium and large according to the number in employees of the enterprise. The micro enterprises have 5 or less employees while the small enterprises have less than 50 full time employees in service (South African National Small Business Amendment Act 26 of 2003).

In a study on small business performances Morrison and Teixeira, (2004) identified the "internal" and "external" contextual factors of an SMTE. The owner-managers and the business systems represent the internal contextual factors, while the competitive environment, and the macro \& micro economic factors, are referred as the external contextual factors as illustrated in Table 1 below (Morrison \& Teixeira, 2004:169).

Table 1: Internal and external contextual factors

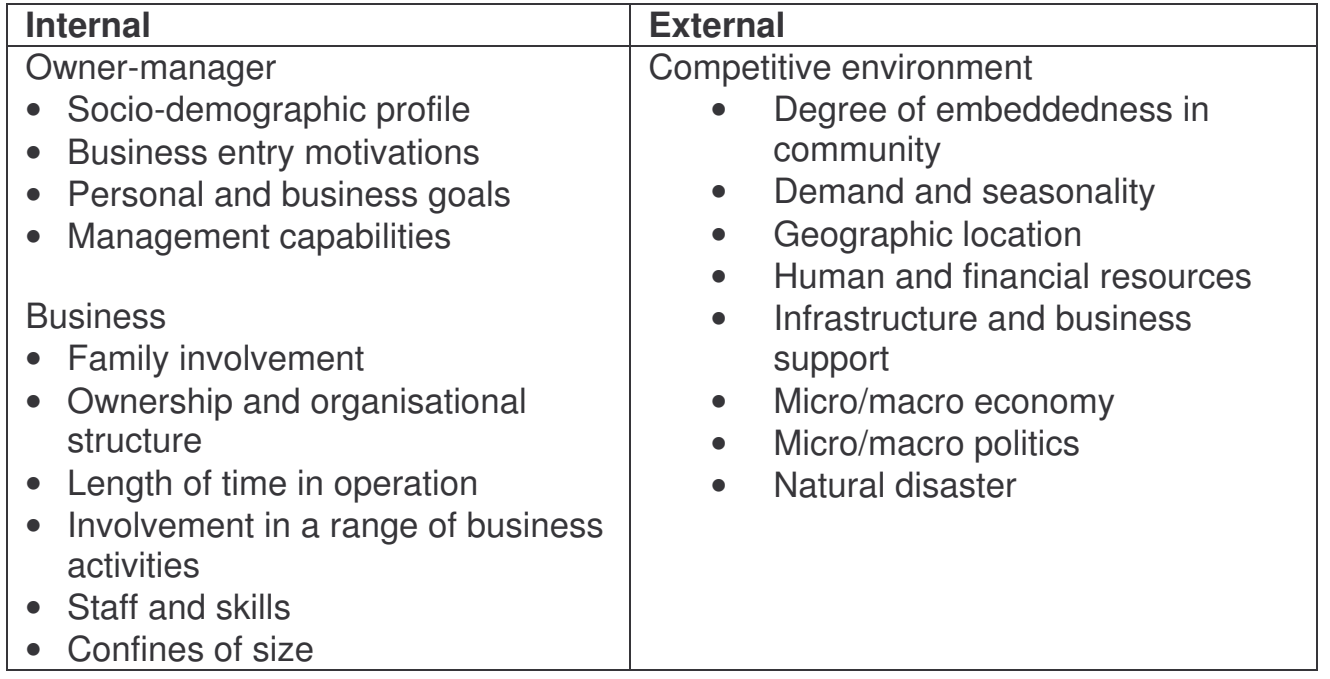

Source: Morrison and Teixeira, (2004:169).

The relationships between the internal and the external contextual factors shown in Table 1 are depicted as the three integrated SMTE subsystems, following the conceptual model of Morrison, et al. (1999: 194), illustrated in Figure 2 below. In small businesses, the overlap between owner-manager and business contextual factors or subsystems is significant. This is due to the business subsystems shown in Table 1, where size of the enterprise is small, with relatively simple structures of the young organization and also limited range of business activities in which the venture engages. The ownermanager manages every functional aspect of the business, thus indicating that the entrepreneurial leadership characteristics of the owner-manager's are vital, for the performance of an enterprise (Peters, 2005: 575-591). The proposed VZMH model demonstrates the conceptual relevance of ethical entrepreneurial leadership (EEL), market orientation (MO) and relationship marketing orientation (RMO), individually and jointly, and the influence that they exert on the performance of an SMTE. Hence the systems thinking principles are used as a method of identifying and measuring each subsystem. 
Figure 2: Business system constituents

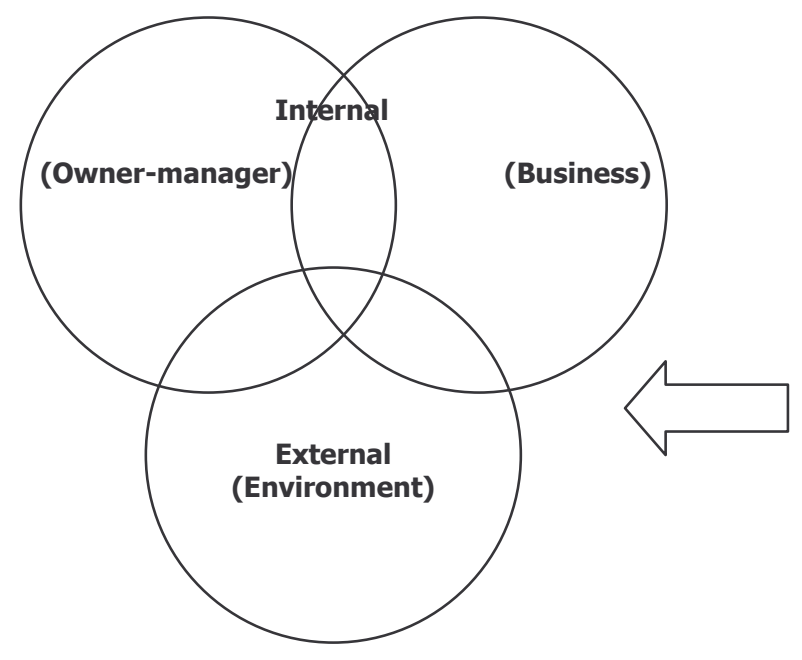

Bigger business

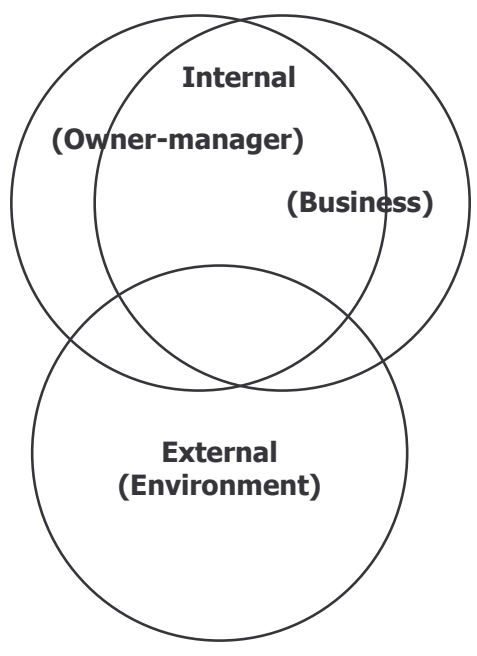

Small business

Source: Adapted from Morrison, et al. (1999:194).

\section{SYSTEMS THINKING AND THE CONCEPTUAL MEASUREMENT MODEL}

The seven groups of systems thinking principles identified by Mulej et al. (2004:54) are illustrated in Table 2 below. The measurement of each subsystem is dependent upon the overarching methodology selected for the study.

Hence, the method of systems thinking principles would be most appropriate to apply in the process of understanding the SMTE systems context and subsequently determining how to measure each subsystem in the VZMH model.

Table 2: Seven groups of systems thinking principles

\begin{tabular}{|c|l|}
\hline No. & Systems/systemic/holistic thinking principles \\
\hline 1 & Interdependence/relations/openness/interconnectedness \\
2 & Complexity and complicatedness \\
3 & Attractors \\
4 & Emergence \\
5 & Synergy/system/synthesis \\
6 & Whole/holism/big picture \\
7 & Networking/interaction and interplay \\
& \\
\hline
\end{tabular}

Source: Adapted from Mulej et al. (2004: 54).

The VZMH model has identified EEL; MO; RMO and SMTE as the primary constructs. While EEL consists of entrepreneurship and leadership dimensions, each of these dimension moreover consist of the various sub-dimensions. Although the model conceptualises EEL as an antecedent of $\mathrm{MO}$ and $\mathrm{RMO}$, which are multi-dimensional constructs, however, $\mathrm{MO}$ and RMO as strategic orientations are conceptualised to moderate the relationship between EEL and SMTE performance, individually and collectively (Van Zyl and Mathur-Helm, (2007:17-24).

Given Conti's (2006:297) reference of systems as "those wholes which are characterised by interactions and by interdependence among their constituent parts", in the VZMH model it would 
therefore signify that EEL; MO; RMO and SMTE performance subsystems, not only act together but are also interdependent in a holistic way. The holism refers to that characteristic of systems, whereby identity is derived from the relations among the systems. Another characteristic of systems, called emergent property, occurs through the relationships between the fundamental components in the interacting systems. These emergent property characteristics are however not reducible to any combination of the properties of the constituent systems (Conti, 2006:298). The emergent property characteristics should therefore be seen as a Gestalt of having value (nature and extent of the interrelationships) more than that of the fundamental characteristics. This principle of systems creates a challenge for the VZMH model to measure and interpret the nature and extent of the interrelationships between the identified constructs, as the model itself is a complex one with at least four multidimensional, interacting subsystems.

The systems complexity refers to those attributes which result from relationships or interdependence between the interacting systems. These attributes that emerge as a result of the mentioned interrelationships between systems are referred to as attractors (Mulej et al., 2004:55). It therefore indicates that the fundamental subsystems within the complex, ethical entrepreneurial leadership system in the VZMH model not only exert influence on the co-constituent subsystems, but also on the other theoretically identified systems (MO, RMO and SMTE performance). Hence, from an empirical point of view these interrelationships should be quantified and interpreted in order to predict the SMTE performance.

\section{ETHICAL ENTREPRENEURIAL LEADERSHIP MEASUREMENT}

Considering, González and Guillén's (2002:152) findings that a leadership construct consists of a technical, psycho-emotive and an ethical dimension, and that the entrepreneurial leadership construct is a combination of leadership and entrepreneurship constructs (Vecchio, 2003:322), the present study integrates ethical, entrepreneurial and leadership dimensions to create the complex Ethical Entrepreneurial Leadership (EEL) construct. With regard to measuring EEL characteristics of small enterprise owner-managers, the paper further proposes an evaluation of the previous reliable measuring instruments to assess entrepreneurial, ethical and leadership characteristics. Therefore, in the present study, the entrepreneurial proclivity instrument of Matsuno, Mentzer and Özsomer (2002:18-32) for entrepreneurship characteristics; the ethical orientation instrument developed by Forsythe (1980:175-184) for the ethical characteristics and the revised self-leadership instrument developed by Houghton and Neck (2002:672-691) to assess self-leadership characteristics, will be evaluated to assess the owner-manager's EEL characteristics.

\section{Entrepreneurial Proclivity}

Matsuno, Mentzer and Özsomer (2002:18-32) explain that entrepreneurial proclivity, a term used interchangeably with the entrepreneurial orientation and entrepreneurial management, refers to the level of entrepreneurship of individuals and the organizations. In a study describing the effects of entrepreneurial proclivity and market orientation on business performance of manufacturing companies in the United States, Matsuno et al. (2002:18-32) used a three dimensional 7-item measure to assess entrepreneurial proclivity in managers. The three distinct dimensions of the entrepreneurial proclivity measure were: innovativeness, pro-activeness and risk-taking propensity. The study randomly selected a sample of 1300 manufacturing companies from a population of approximately 600000 to approach 300 in a pre-test and the remaining 1000 in the final test. The response rates for the pre and the final tests were $31.3 \%$ and $38.76 \%$ respectively. The fit statistics of a confirmatory factor analysis (CFA) on the final data set in the study were good with a chi-square $\left(\mathrm{X}^{2}\right)$ $=14.535$; degrees of freedom (d.f.) $=11$; goodness-of-fit index $(\mathrm{GFI})=0.988$; adjusted goodness-of-fit index $(\mathrm{AGFI})=0.97$; normed fit index $(\mathrm{NFI})=0.982$ and comparative fit index $(\mathrm{CFI})=0.995$, in support of the second-order factorial structure of the entrepreneurial proclivity construct. The entrepreneurial proclivity construct was one of five latent constructs analysed in this study. Acceptable levels of convergent and discriminant validity were found leading to acceptance of the fit for the hypothesised structural equation model. Results of the study indicated that:

- The greater the entrepreneurial proclivity, the greater the level of market orientation;

- The entrepreneurial proclivity has an indirect, but positive effect on business performance, and 
- The entrepreneurial proclivity is a significant and positive antecedent of market orientation resulting in a positive business performance (Matsuno et al., 2002:26).

Based on the acceptable levels of the abovementioned fit statistics as well as the acceptable levels of convergent and discriminant validity, the three dimensional, 7-item entrepreneurial proclivity measurement instrument was found to be reliable for measuring the entrepreneurial characteristics. Hence, it can be used to answer the following research questions, as referred to in the conceptual measurement model (Figure 1) within the context of South African SMTE's:

- Are the owner-manager's entrepreneurial characteristics positively and directly related to the SMTE market orientation?

- Are the owner-manager's entrepreneurial characteristics positively and directly related to SMTE relationship marketing orientation?

- Are the owner-manager's entrepreneurial characteristics positively and directly related to four relative measures of the tourism business performance?

- Are the owner-manager's entrepreneurial characteristics positively and indirectly related to the four relative measures of the tourism business performance mediated by $\mathrm{MO}$ and $\mathrm{RMO}$ ?

- Are the owner-manager's entrepreneurial characteristics positively and directly related to the level of ethical orientation displayed?

- Are the owner-manager's entrepreneurial characteristics positively and directly related to the level of self-leadership displayed?

\section{Ethical Orientation}

Karande, Rao and Singhapakdi's study (2002:770) highlights Idealism and relativism as the important predictors of moral judgement identified by Forsythe (1980:175-182). They developed an instrument consisting of two separate scales for relativism and idealism, to measure an individual's ethical orientation. Catlin and Maupin (2004:291) suggested that the ethics position questionnaire (EPQ) of Forsythe (1980:175-182) has been successfully used in a wide variety of studies which, amongst others include the business and management domains, which is relevant to this paper. While EPQ's idealism scale measures an individual's attitude towards causing harm to others, the relativism scale on the other hand measures an individual's attitude to universal moral principles and rules (Comunale, Sexton \& Gara, 2006:639). Since one of the purposes of this paper is to indicate how and with which instrument the levels of ethical orientation of the South African SMTE owner-managers could be reliably measured, it would be significant to understand how the SMTE business performance relates to an owner-manager's relativism and idealism orientations. If tested upon, how will the moral judgement ability of the South African SMTE owner-managers relate to their entrepreneurial orientation and self-leadership characteristics? And how will the moral judgement ability or ethical orientation of the owner-managers relate to the SMTE business performance as moderated by their specific choice of blend of $\mathrm{MO}$ and RMO as the strategic orientations?

The EPQ consists of 20 items, of which ten measure relativism and the rest measure idealism. Respondents are required to indicate their agreement or disagreement on each of the 20 items on a 7-point Likert scale. The mean score of the respective relativism and idealism scales indicates the ethical orientation of the respondents (Monga, 2005:637). Measures of validity and reliability of the EPQ in other studies will be used as an indicator of the usefulness of this instrument to measure the ethical orientation of owner-managers of South African SMTE's. For this purpose this paper will evaluate two previous studies, where the EPQ was successfully applied.

In the first study, Karande et al. (2002:768-791) investigated moral philosophies of marketing managers by comparing data from American, Australian and Malaysian cultures. The EPQ was used to measure moral philosophies of the marketing managers. Karande et al. (2002:772) justify their decision to use the EPQ based on well established recognition in the literature that relativism and realism influence ethical decision-making. The study found and determined the convergent validity 
when each of the EPQ constructs exhibited uni-dimensional factor structures and had significant factor loadings $(p<0.01)$ greater than 0.5 for all items of the two constructs. Discriminant validity for the EPQ constructs was measured by comparing the fit with the correlation between the idealism and relativism constructs, as opposed to being free. Moreover, there was no statistical difference in the fit based on a chi-square test, hence discriminant validity was determined. Cronbach alpha was used to assess reliability of the EPQ measure, which ranged between 0.81 and 0.89 and was well above the recommended level of 0.70 suggested by Nunnaly (1978:84). Hence Karande et al. (2002:768-791) found the EPQ acceptable and their findings indicate that:

- There are statistically significant differences between the idealism and relativism scores of different cultures.

- The corporate ethical values positively influence marketing manager's idealism scores and negatively influence manager's relativism scores.

- The women marketing managers are more idealistic than their male counterparts, however, no significant gender differences were found on the relativism scale.

- There are significant differences between different age groups on the relativism scale. The higher the age the lower the relativism score. No significant differences were found between different age groups on the idealism scale (Karande et al., 2002: 784-5).

In the second study, Monga (2005:632-644) investigated some ethical positions of Indian manufacturing managers in the state of Punjab by using the EPQ. An understanding of the ethical beliefs and values of the Punjabi managers was regarded important and a pre-requisite for developing relationships with their personnel (Monga, 2005: 637). According to Monga (2005:637) the EPQ has demonstrated acceptable levels of internal consistency and has been successfully applied in different cultural contexts. Consistent with Forsythe's (1980) taxonomy, this study classified respondents with high scores on both the idealism and relativism scales of the EPQ as situationists. Hence, those high on the idealism scale but low on the relativism scale were regarded as absolutists, while those with low idealism and high relativism scores were regarded as subjectivists. Moreover those who were low on both idealism and relativism scales were regarded as exceptionists (Monga, 2005:637). The SPSS (Statistical Programme for Social Sciences) was used to calculate relevant idealism and relativism scores in order to classify respondents as situationists, absolutists, subjectivists or exceptionists. The Cronbach alpha reliability scores for idealism and relativism were 0.7 and 0.8 respectively, and were acceptable according to Nunnaly (1978:84). Results from this study indicate that:

- $99.4 \%$ managers scored high on the idealism scale.

- $81.8 \%$ managers scored high on the relativism scale.

- $\quad 78.9 \%$ managers were classified as situationists.

- $\quad 20.5 \%$ managers were absolutists.

- $\quad$ There is a link between the levels of education and high idealism scores of Punjabi managers (Monga, 2005:640).

The EPQ could therefore be used to answer the following questions emanating from the conceptual measurement model (Figure 2) within the context of South African SMTE's:

- Is an owner-manager's ethical orientation positively and directly related to the level of selfleadership?

- Is an owner-manager's ethical orientation positively and directly related to the MO?

- Is an owner-manager's ethical orientation positively and directly related to the RMO?

- Is an owner-manager's ethical orientation positively and directly related to the four relative measures of tourism business performance?

- Is an owner-manager's ethical orientation positively and indirectly related to the four relative measures of tourism business performance mediated by the $\mathrm{MO}$ and the RMO? 


\section{Self-leadership}

Self-leadership is a self-influencing process through which people achieve self-direction and selfmotivation necessary for high performance. Self-leadership is based on the application of behavioural and cognitive strategies. These strategies are grouped into behaviour-focussed strategies; natural reward strategies and constructive thought pattern strategies (Neck \& Houghton, 2006:271). Selfleadership is about people who learn to lead themselves and others. Individuals with high selfleadership levels can lead others to support their new ideas and solutions (Carmeli, Meitar \& Weisberg, 2006:79). Houghton and Neck (2002:672-691) developed a three dimensional 35-item revised self-leadership questionnaire (RSLQ) and used the exploratory factor analysis method (EFA) to assess its factor structure.

The EFA results suggest a very stable factor structure for the RSLQ (Houghton \& Neck, 2002:672691). A superior fit of the second order factor model of the RSLQ indicated that it measures selfleadership as specified by the self-leadership theory. The Confirmatory factor analysis method (CFA) and the structural equation modelling method (SEM) were used to assess the fit of the revised selfleadership scale. The construct validity was determined through the CFA. Results from the EFA and CFA determined RSLQ as a fairly reliable and valid measurement instrument for assessing selfleadership (Houghton \& Neck, 2002:685).

The RSLQ was used in a study by Carmeli et al. (2006:75-90) which investigates the relationship between self-leadership characteristics and the innovative behaviour. In a pilot study, the RSLQ was administered on a sample of 100 randomly selected employees in Israeli companies. The validity and reliability measures of the RSLQ were acceptable with a Cronbach alpha above the suggested 0.70 . In the main study, the RSLQ was administered on a sample of 250 employees of whom $87 \%$ responded. Cronbach alphas for the scales of the RSLQ (behaviour-focussed strategies; natural reward-focussed strategies; constructive thought-focussed strategies and general self-leadership strategies) were $0.85 ; 0.52 ; 0.83$ and 0.92 respectively (Carmeli et al., 2006:82). This study used the structural equation modelling (SEM) technique to estimate the research model. The following criteria of goodness-of-fit indices were used to asses the model fit: $X^{2} /$ d.f. ratio to be less than 3; RFI, NFI, CFI and TLI (Tucker-Lewis coefficient) to be greater than 0.90 and RMSEA (Root Mean Square Error of Approximation) to be up to 0.05 and acceptable at 0.08 . A Chi-square of 15.55 on 11 degrees of freedom and $\mathrm{CFI}=0.98 ; \mathrm{NFI}=0.96 ; \mathrm{RFI}=0.91 ; \mathrm{TLI}=0.97$ and $\mathrm{RMSEA}=0.04$ were obtained, which indicated that the hypothesized model corresponded well with the data (Carmeli et al., 2006:83). Based on the above mentioned successful application of the RSLQ this instrument is recommended to assess the self-leadership characteristics of the South African SMTE owner-managers.

Since the abovementioned results conclude that self-leaders display relatively high levels of innovative behaviour (Carmeli et al., 2006:85), the RSLQ could be used to answer the following questions emanating from the conceptual measurement model (Figure 2) within the context of South African SMTE's:

- Is an owner-manager's self-leadership positively and directly related to the MO?

- Is an owner-manager's self-leadership positively and directly related to the RMO?

- Is an owner-manager's self-leadership positively and directly related to the four relative measures of tourism business performance?

- Is an owner-manager's self-leadership positively and indirectly related to the four relative measures of tourism business performance mediated by $\mathrm{MO}$ and $\mathrm{RMO}$ ?

\section{STRATEGIC ORIENTATIONS MEASUREMENT}

According to Tse et al. (2004:1160), MO and RMO are strategic orientations. Kohli and Jaworski (1990: 1-19) and Narver and Slater (1990: 18-35), amongst others, have developed the reliable measurement instruments for MO. Sin et al. (2002:656-676) on the other hand have developed an instrument to assess RMO reliability. Hence, this paper presents an evaluation of the measurement instruments of Kohli and Jaworski (1990:1-19) and Narver and Slater (1990:18-35) as well as the 
RMO measurement instrument of Sin et al. (2002:656-676) as relevant measurement instruments to assess the $\mathrm{MO}$ and $\mathrm{RMO}$ characteristics of small tourism owner-managers in South Africa.

\section{Market Orientation}

According to Kohli and Jaworski (1990:2), Market orientation is the organisation-wide generation of market intelligence, focussing on the current and future needs of the customers, the dissemination of intelligence through the organisation and the organisation-wide responses to this intelligence. Alternatively, Narver and Slater (1990:19) define the market orientation with three behavioural components, namely, the customer orientation, the competitor orientation and the inter-functional coordination. The Kohli and Jaworski (1990:2) definition centres around information and information management, whereas the Narver and Slater (1990:19) definition focuses more on a broader, organisational behaviour perspective (Javalgi et al., 2006:13). For the present study, it is more relevant to assess the owner-manager's broader marketing behavioural viewpoints than to assess their information and information management orientations. Therefore the paper will focus on the Narver and Slater's (1990:18-35) measurement model, that only has 15 items which are fewer than the model of Kohli and Jaworski (1990:1-19) with 22 items. Furthermore, the Narver and Slater (1990:18-35) scale in general, is more advanced than the Kohli and Jaworski (1990:1-19) scale as it explains variations in measures of business performance (Tse, Sin, Yau, Lee \& Chow, 2004:1162) and describes market orientation as one of the strategic behaviour's which leads to the competitive advantage (Osuagwu, 2006:612), that eventually leads to business performance.

In their study Hooley, Fahy, Greenley, Beracs, Fonfara and Snoj, (2003:86-106) investigated the influence of the $\mathrm{MO}$ in service firms on business performance. They used the 14-item Narver and Slater (1990:18-35) scale to evaluate the relationship of MO with business performance of 346 respondents from European transition economy firms. The Cronbach alpha reliability coefficient for the $\mathrm{MO}$ scale was acceptable at 0.85 and item-to-total correlations were all above 0.30 as suggested by Nunnaly (1978:84). Convergent and nomological validity of the MO scale was also found to be acceptable, suggesting that all items of the MO scale functioned according to the theoretical prediction (Hooley et al., 2003:102). The Narver and Slater (1990:18-35) scale was therefore found to be an acceptable measure of the MO. Hence, the instrument can be used to assess the MO of South African SMTE owner-managers.

Given that there is a direct and positive relationship between the $M O$ and both objective and subjective business performance measures (Hooley et al., 2003:102), the MO instrument can be used to answer the following questions arising from the conceptual measurement model (Figure 2) within the context of South African SMTE's:

- Is an owner-manager's MO positively and directly related to the four relative measures of the tourism business performance?

\section{Relationship Marketing Orientation}

The RMO measures the extent to which an enterprise engages in developing a long-term relationship with its customers (Tse et al., 2004:1162); moreover a business that adopts RMO will improve its business performance (Sin et al., 2002:656). Therefore, adoption of the RMO as a strategic orientation for the SMTE owner-managers would contribute to the improved perception of superior customer service, while simultaneously contributing to making profit and creating competitive advantage (Sin et al., 2002:658). The RMO is a multidimensional construct, consisting of the following six behavioural components: trust; bonding; communication; shared value; empathy; and reciprocity (Van Zyl \& Mathur-Helm, 2007:20).

Sin et al. (2002) developed a 22-item RMO measurement instrument by following acceptable procedures suggested by Churchill (1979) and Zaichkowsky (1985). Cronbach alpha reliability coefficients for the RMO scale and the individual subscales were all above the 0.70 standard hence reliable as suggested by Nunnaly (1978:84). Sin et al. (2002:668) found evidence of convergent validity, discriminant validity and nomological validity in support to the acceptance of construct validity for the six-dimensional model of the RMO. The study also found correlation coefficients between RMO and four measures of business performance (sales growth; customer retention; return on investment and market share) as positive and significant (at $p<0.05$ ). This holds intrinsic value for the 
proposed measurement of SMTE owner-managers using RMO in relation to tourism business performance.

Another study by Sin et al. (2005:36-57) investigated the moderating effect of economic ideology on the relationship between the blend of $\mathrm{MO}$ and $\mathrm{RMO}$ as the strategic orientations and business performance. The study compared the effects of $\mathrm{MO}$ and RMO on the business performance in Hong Kong's more stable market-driven economy with Mainland China's more unstable, regulated and transitional economy, and found that the application of RMO as a strategy is more dominant than $\mathrm{MO}$ in highly uncertain economic environments to achieve business performance like in Mainland China. Conversely, the impact of $\mathrm{MO}$ as a customer-driven strategy on business performance is more dominant than RMO (relationship-building) in more stable economic environments as in Hong Kong. The significance of this study in terms of the use of both $\mathrm{MO}$ and $\mathrm{RMO}$ in tandem is that the Cronbach alpha reliability coefficients for both $\mathrm{MO}$ and $\mathrm{RMO}$ scales were above the 0.70 acceptance levels (Sin et al., 2005:44). Acceptable levels of the convergent and discriminant validity were also established to suggest that the MO and the RMO could be reliably used in tandem (Sin et al., 2005:45).

Based on the abovementioned evidence, the RMO instrument can be used to answer the following questions emerging from the conceptual measurement model (Figure 1) within the context of South African SMTE's:

- Is an owner-manager's MO inversely related to his/her RMO?

- Is an owner-manager's RMO positively and directly related to the four relative measures of the tourism business performance?

\section{CONSTRUCTION OF THE MEASUREMENT INSTRUMENT}

The abovementioned measurement instruments (Matsuno et al., 2002; Forsythe, 1980; Houghton \& Neck, 2002; Narver \& Slater, 1990; Sin et al., 2002 and Wood, 2002;2006) have been conceptually identified as valid and reliable tool to be included in the construction of a versatile, multifaceted and complex measurement instrument. This instrument should be able to empirically test the combined effects and influence of predictors on the SMTE performance in South Africa. The reliability and validity of this conceptually constructed complex measurement instrument should now be verified empirically. The instrument could use a 7-point, Likert-type scale, with "mostly agree" to "mostly disagree" as the highest and lowest points. This conceptual complex instrument consists of a total of 101 items. The 4-item performance construct could be assessed against 9 controlled variables, which will include: venture age; respondent age; respondent qualifications; respondent experience; gender; respondent home language; location of business; number of employees and survival/lifestyle/growth orientation.

\section{SMTE PERFORMANCE MEASUREMENT}

The present study selects four self-reporting, relative tourism business performance variables from the past studies (Wood, 2002;2006 and Lerner \& Harber, 2000), which are: number of customers, number of employees, profitability of the ventures and amount of customer spending (turnover). The owner-managers of SMTE's will be required to record their perceptions regarding the performance of their organisations consistent with the four identified tourism performance variables relative to that of their competitors. According to Matsuno et al. (2002:24) previous research indicate that the SME's are hesitant to provide objective performance data and that subjective measures have been shown to correlate well with objective measures of performance, therefore present study chooses the subjective performance measures.

In their study on Israeli tourism, Lerner and Haber (2000:84) established that numbers of tourists (nights of accommodation or visits) constitute a demand measure, which reflects the revenues of a tourism business. It indicates a correlation between the numbers of customers of an enterprise and the amount of revenue generated for that enterprise. However, this can only be true if the customers pay a fixed rate for the essential services. In cases where there are diverse products and service offerings, it might be relevant to know the amount of revenue customers spend. 
Rahman cited in Wood (2002:203) used a combined organisational performance measure which included revenue, profit and number of customers in an Australian tourism study, to assess business performance. According to Wood (2006: 445), owner-managers have different objectives for being in the tourism business, which are survival, lifestyle, or growth. If an enterprise has a growth objective, then the number of customers, number of employees, amount of customer spending and enterprise profitability, would be important. For lifestyle and survival objectives the number of employees would not be significant for the performance, however, number of customers and the amount of customer spending and profitability would be vital. Since growth and employment creation are linked, for the present study, it is very important to identify the extent and the numbers of tourism enterprises that are actually growth-orientated.

\section{DATA ANALYSIS TECHNIQUE}

As an appropriate technique to determine, the nature and extent of the interrelationships between the latent constructs in the conceptualized VZMH model, the method of Structural equation modelling (SEM) (Jöreskorg, 1993 and Hair, Anderson, Tatham, \& Black, 1998) will be used. This method consists of the entire range of models including, covariance analysis, latent variable analysis and confirmatory factor analysis, which provides the ability to accommodate multiple interrelated dependent relationships in a single model.

The present study identifies this method to be a useful technique as it allows estimation of many equations simultaneously through unification, implying that the dependent variable in one equation can be the independent variable in another (Hair et al., 1998:586).

\section{IMPLICATIONS}

Aim of the present paper was to investigate personal qualities of the small business owners, the businesses, and the environment of the businesses, by using systems approach, identifying the complex interplay between the varying characteristic in the VZMH model. The study conceptually brings together the diverse perspectives in formulating a more comprehensive and unified instrument for measuring entrepreneurship performance in the small tourism industry in South Africa.

The conceptual model measures entrepreneurial leadership and can distinguish between successful (performing) and unsuccessful (non-performing) owner-managers of such ventures. Moreover, the instrument is aimed at providing insights into the kind of skills that a particular entrepreneurial leader and/or an owner manager of a small tourism enterprise needs in order to perform optimally in a complex and competitive environment, by establishing the exact nature and extent of the combined relationships between the distinct components of entrepreneurial leadership such as: self-leadership, ethical orientation, entrepreneurial proclivity, market orientation, relationship marketing orientation and small business performance, which no previous models did.

The study will add immense value since South Africa is one of the most popular tourist destinations that stand a good prospect of expanding its opportunities for the existing and upcoming tourism ventures. Hence owners, managers and leaders of the small tourism enterprises, demonstrating leadership characteristics such as high internal locus of control, autonomy and achievement drive, will be able to build high performing future businesses, through awareness of such characteristics and acquiring them through skills development.

\section{CONCLUSION}

The present study develops a model of entrepreneurial leadership that can distinguish between successful and unsuccessful owners of small and micro tourism enterprises within South African context.

The complex, comprehensive measurement instrument was constructed by a combination of various dimensions such as: entrepreneurial proclivity instrument (Matsuno et al., 2002); ethical orientation instrument (Forsythe, 1980); revised self leadership instrument (Houghton \& Neck, 2002); market orientation instrument (Narver \& Slater, 1990) and relationship marketing orientation instrument (Sin et al., 2002). Moreover, four subjective, self reporting items were used from Wood (2002;2006) and Lerner and Harber (2000), to help in identifying the vital entrepreneurial characteristics described 
through a combination of different dimensions. However, the reliability and validity of the construct still needs to be re-assessed, subsequent to its use.

Present study found a model that can signify the link between personal entrepreneur leadership qualities and the small business performance. This significance will help the future small tourism enterprises to understand how to follow the journey from being a good enterprise to a great one.

Structural equation modelling was identified as a suitable technique to determine the nature and extent of the link between the latent constructs in the conceptualized Van Zyl and Mathur-Helm (2007) model.

\section{LIMITATIONS \& FUTURE SCOPE}

This paper conceptually constructed a complex measurement instrument that could be used to asses the interrelationships identified in the Van Zyl and Mathur-Helm (2007) model. Present study is limited to constructing the performance measurement instrument for SMTE and identifying an appropriate data analysis technique for testing the complex variables in the VZMH (2007) model, which is the structural equation modelling method. Future studies will empirically verify the validity and reliability of this conceptual complex measurement instrument within the South African SMTE context.

\section{REFERENCES}

Carmeli A, Meitar R \& Weisberg J. 2006. Self-leadership skills and innovative behaviour at work. International Journal of Manpower, 27(1):75-90.

Catlin DW \& Maupin JR. 2004. A two cohort study of the ethical orientations of state police officers. Policing: An International Journal of Police Strategies \& Management, 27(3):289-301.

Churchill GA. Jr. 1979. A paradigm for developing better measures of marketing constructs. Journal of Marketing Research, 16(1):64-73.

Collins J. 2001. Good to Great Companies. New York: Harper Collins.

Comunale CL, Sexton TR \& Gara SC. 2006. Professional ethical crisis: A case study of accounting majors. Managerial Auditing Journal, 21(6):636-656.

Conti T. 2006. Quality thinking and systems thinking. The TQM Magazine, 18(3):297-308.

Forsythe DR. 1980. A taxonomy of ethical ideologies. Journal of Personality and Social Psychology, 39(1):175-184.

González TF \& Guillén M. 2002. Leadership ethical dimension: a requirement in TQM implementation. The TQM Magazine, 14(3):150-164.

Hair JF, Anderson RE, Tatham RL \& Black WC. 1998. Multivariate Data Analysis. New Jersey: Prentice-Hall.

Hooley G, Fahy J, Greenley G, Beracs J, Fonfara K \& Snoj B. 2003. Market orientation on the service sector of the transition economies of central Europe. European Journal of Marketing, 37(1/2): 86-106.

Houghton JD \& Neck CP. 2002. The revised self-leadership questionnaire: Testing a hierarchical factor structure for self-leadership. Journal of Managerial Psychology, 17(8):672-691.

Javalgi RG, Martin CL \& Young RB. 2006. Market research, market orientation and customer relationship management: a framework and implications for service providers. Journal of Services Marketing, 20(1):12-23.

Jöreskorg K. 1993. Testing structural equation models. In Bollen, K.A. \& Long, J.S. (Eds.). Testing structural equation models. Newbury Park: Sage. 
Karande K, Rao CP \& Singhapakdi A. 2002. Moral philosophies of marketing managers: A comparison of American, Australian and Malaysian cultures. European Journal of Marketing, 36(7/8):768-791.

Kohli A \& Jaworski B. 1990. Market orientation: the construct, research propositions and managerial implications. Journal of Marketing, 54(April):1-18.

Lerner M \& Haber S. 2000. Performance factors of small tourism ventures: the interface of tourism, entrepreneurship and the environment. Journal of Business Venturing, 16: 77-100.

Matsuno K, Mentzer JT \& Özsomer A. 2002. The effects of entrepreneurial proclivity and market orientation on business performance. Journal of Marketing, 66(July):18-32.

Monga M. 2005. Value orientations: a case study of north Indian manufacturing managers. Journal of Management Development, 24(7):632-644 .

Morrison A, Rimmington M \& Williams C. 1999. Entrepreneurship in the hospitality, tourism and leisure industries. Oxford: Butterworth-Heinemann.

Morrison A \& Teixeira R. 2004. Small business performance: a tourism sector focus. Journal of Small Business and Enterprise Development, 11(2):166-173.

Mulej M, Potocan V, Zenko Z, Kajzer S, Ursic D, Knez-Riedl J, Lynn M \& Ovsenik J. 2004. How to restore Bertalanffian systems thinking. Kybernetes, 33(1):48-61.

Narver JC \& Slater SF. 1990. The effect of a market orientation on business profitability. Journal of Marketing, 54(4):20-35.

Neck CP \& Houghton JD. 2006. Two decades of self-leadership theory and research. Past developments, present trends and future possibilities. Journal of Managerial Psychology, 21(4):270295.

Nunnaly JC. 1978. Psychometric theory. New York: MacGraw-Hill.

Osuagwu L. 2006. Market orientation in Nigerian companies. Marketing Intelligence and Planning, 24(6):608-631.

Peters M. 2005. Entrepreneurial skills in leadership and human resource management evaluated by apprentices in small tourism businesses. Education + Training, 47(8/9):575-591.

Republic of South Africa. 2003. National Small Business Amendment Act, (Act 26 of 2003). Pretoria: Government Printer.

Sin LYM, Tse ACB, Yau OHM, Lee JSY \& Chow RPM. 2002. The effect of relationship marketing orientation on business performance in a service-oriented economy. Journal of Services Marketing, 16(7): 656-676.

Sin LYM, Tse ACB, Yau OHM, Lee JSY \& Chow RPM. 2005. Market orientation, relationship marketing orientation, and business performance: the moderating effects of economic ideology and industry type. Journal of International Marketing, 13(1):36-57.

Sin LYM, Tse ACB, Yau OHM, Lee JSY \& Chow RPM. 2004. A firm's role in the marketplace and the relative importance of market orientation and relationship marketing orientation. European Journal of Marketing, 38(9/10):1158-1172.

Van Zyl HJC \& Mathur-Helm B. 2007. Exploring a conceptual model, based on the combined effects of entrepreneurial leadership, market orientation and relationship marketing orientation on South Africa's small tourism business performance. South African Journal of Business Management, 38(2):17-24. 
Vecchio RP. 2003. Entrepreneurship and leadership: common trends and common threads. Human Resource Management Review, 13(2003):303-329.

Wood EH. 2002. An analysis of the predictors of business performance in small tourism and hospitality firms. International Journal of Entrepreneurship and Innovation, 3(3):201-210.

Wood EH. 2006. The internal predictors of business performance in small firms. Journal of Small Business and Enterprise Development, 13(3):441-453.

Zaichkowsky JL. 1985. Measuring the involvement construct. Journal of Consumer Research, 12(3):341-352. 